\title{
Polymerization of Acrylonitrile Initiated by Cerium(IV) / p-Aminoacetophenone Redox System - A Kinetic Study
}

\author{
M. PALANIVELU* and A. AFROOS BANU \\ P.G and Research Department of Chemistry, \\ Khadir Mohideen College, Adirampattinam - 614 701, Tamilnadu, India \\ nigishpalani@yahoo.in
}

Received 28 August 2016 / Accepted 23 September 2016

\begin{abstract}
The kinetics of aqueous polymerization of acrylonitrile initiated by the $\mathrm{Ce}(\mathrm{IV}) / p$-aminoacetophenone ( $\mathrm{Ce}(\mathrm{IV})$ - AAP) redox system in aqueous solution of sulfuric acid medium has been studied under nitrogen atmosphere in the temperature range $30-80{ }^{\circ} \mathrm{C}$. The rate of polymerization $(R p)$ and the disappearance of Cerium(IV) have been measured at various concentrations of monomer, initiator, activator and sulfuric acid. The temperature dependence of the rate was studied and the activation parameters were computed using Arrhenius plot. A mechanism consistent with the experimental data is proposed and discussed.
\end{abstract}

Keywords: Acrylonitrile, Ceric ion, $p$-Aminoacetophenone, Radical polymerization.

\section{Introduction}

Certain inorganic transition metal ions in their higher valence states coupled with easily reducible organic substrates act as potential initiators for the redox polymerization of vinyl monomers. The various initiating system involving cerium(IV) ion coupled with several organic substrates has been used for the oxidation of large number of organic substrates. $\mathrm{Ce}(\mathrm{IV})$ ion has been used for the oxidation of many organic compounds, in the form of cerium(IV) ammonium nitrate, cerium(IV) ammonium sulfate, cerium(IV) sulfate, and ceric perchlorate $^{1}$. The oxidation of alcohols by $\mathrm{Ce}(\mathrm{IV})$ is believed to be produced by disproportionation of coordination of complexes. According to the complex mechanism, unimolecular disproportionation of complex yields a cerrous ion, a proton, and a free radical on the alcohol substrate ${ }^{2,3}$. Ce(IV) ion either alone or in combination with various organic reducing agents such as alcohols ${ }^{4}$, acids ${ }^{5}$, amides ${ }^{6}$, aldehydes ${ }^{7}$ and ketones ${ }^{8}$ has been used to initiate vinyl polymerization. The polymerization of acrylonitrile by $\mathrm{Ce}(\mathrm{IV})$-glucose system was studied by Padhi and Singh ${ }^{9,10}$. It is known that $\mathrm{Ce}(\mathrm{IV})$ is an one electron oxidant capable of oxidizing compound in sulfuric acid. Oxidation of any substrate by $\mathrm{Ce}(\mathrm{IV})$ occur through a single electron transfer from the substrate to the oxidant ${ }^{11}$. The mechanism of 
oxidation of cerium in many cases is simpler than the cases with other transition metal ions such as chromate, manganite ion etc. In the paper we have made an attempt to study polymerization of acrylonitrile initiated by Cerium(IV) / p-aminoacetophenone (Ce(IV) - AAP) redox system.

\section{Experimental}

The monomer (AN) was purified by the usual procedures ${ }^{12}$. Sulfuric acid AR grade was used without further purification. $p$-Aminoacetophenone (AR, E.Merck) were used as purchased. The stock solutions of the ligands were prepared in aqueous acetic acid. Water doubly distilled over alkaline permanganate was employed in the preparation of the reagents and solutions. The appropriate quantities of a reaction mixture that containing ceric ammonium sulfate, reducing agent and sulfuric acid were placed in clean conical flasks mounted in a rocking thermostat. The monomer and reducing agent were introduced under $\mathrm{N}_{2}$ atmosphere and the reaction flasks were sealed. The polymerization was allowed to proceed at $40{ }^{\circ} \mathrm{C}$ in the dark in a thermostat. The polymerization reactions started almost instantaneously, indicated by the appearance of turbidity that increased with the progress of polymerization ultimately the polymers precipitated out. After desired intervals the polymerization were halted by adding $10 \mathrm{~mL}$ of $1 \%$ ferrous ammonium sulfate. The precipitated polymer were filtered off on sintered glass crucible, washed repeatedly with water and dried to constant weight at $60{ }^{\circ} \mathrm{C}$ in a vacuum oven. The polymer yield was determined gravimetrically. The rate of polymerization $(R p)$ was calculated from the weight of the polymer formed by using the equation:

$$
R p=1000 \mathrm{~W} / \mathrm{vtM}
$$

Where $\mathrm{W}=$ weight of the polymer in grams, $\mathrm{v}=$ volume of the reaction mixture in milliliters, $\mathrm{t}=$ reaction time in seconds, $\mathrm{M}=$ molecular weight of the monomer.

\section{Results and Discussion}

The polymerization of acrylonitrile was carried out with Ce(IV) in the absence of the activator, the polymerization process markedly decreased. The polymerization of acrylonitrile by $\mathrm{Ce}(\mathrm{IV})-\mathrm{AAP}$ redox system occurred at a measurable rate at $40{ }^{\circ} \mathrm{C}$.

\section{Effect of monomer concentration on polymerization rate}

The rate of polymerization was investigated by varying the concentration of monomer, acrylonitrile (AN) from 0.10 to $0.50 \mathrm{~mol} / \mathrm{L}$. (Table 1) at $40{ }^{\circ} \mathrm{C}$, keeping the concentrations of initiator (Ce(IV)), ligand ( $p$-aminoacetophenone) and sulfuric acid constant.

Table 1. Effect of monomer concentration on polymerization rate

$\left[\mathrm{Ce}(\mathrm{IV})=0.0025 \mathrm{M},[\mathrm{AAP}]=0.002 \mathrm{M},\left[\mathrm{H}^{+}\right]=0.01 \mathrm{M}\right.$, Temperature $=40^{\circ} \mathrm{C}$, Time $=$


From Table 1, it is found that the percentage conversion increases steadily with an increase of monomer concentration. The order dependence of the rate of polymerization on monomer concentration was determined by the plot of $\log R p$ versus $\log$ [AN] with a linear $(\mathrm{r}=0.993)$ slope value is 1.55 (Figure 1). The reaction order is greater than unity with respect to monomer concentration. The order nearly 1.5 dependence of the rate of polymerization on monomer concentration as confirmed by the double logarithmic plot has widely been reported in redox initiated polymerization systems ${ }^{13}$. The order 1.5 dependence of monomer concentration in the present study is contrary to the observations noted in the case of polymerization initiated by the glycerol- $\mathrm{V}(\mathrm{V})$ redox system ${ }^{14}$. Though both $\mathrm{V}(\mathrm{V})$ and $\mathrm{Ce}(\mathrm{IV})$ are one electron oxidants, the oxidation potential of $\mathrm{Ce}(\mathrm{IV})$ is much higher than $\mathrm{V}(\mathrm{V})$ and ceric ion is capable of initiating vinyl polymerization even in the absence of a reducing agent, while $\mathrm{V}(\mathrm{V})$ ion is not.

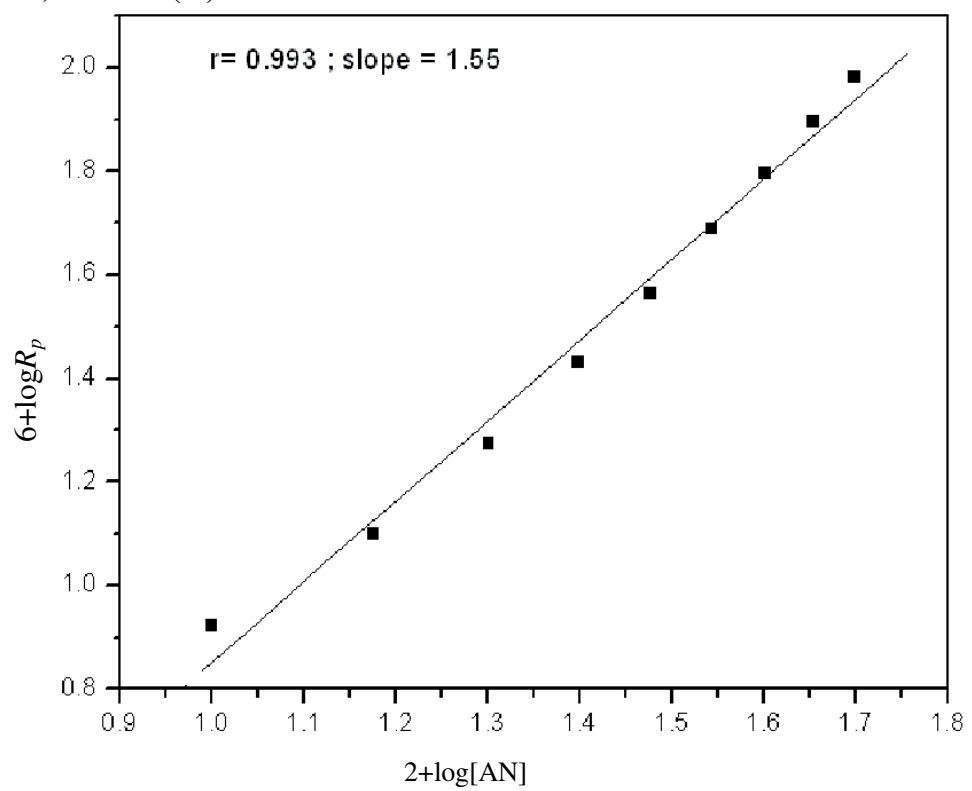

Figure 1. Effect of monomer concentration on the rate of polymerization

\section{Effect of initiator concentration on polymerization rate}

The rate of polymerization was measured with different initiator concentrations at a fixed concentration of monomer $(0.25 \mathrm{M})$, ligand $(0.002 \mathrm{M})$, sulfuric acid $(0.01 \mathrm{M})$ at $40{ }^{\circ} \mathrm{C}$ for $60 \mathrm{~min}$. duration. The effect of concentration of initiator $(\mathrm{Ce}(\mathrm{IV})$ on rate of polymerization was studied by varying the [Ce(IV)] in range from 0.0025 to $0.05 \mathrm{M}$ (Table 2). The $R p$ increases with the concentration of initiator. A plot of $\log R p$ $v s . \log [\mathrm{Ce}(\mathrm{IV})]$ is linear $(\mathrm{r}=0.993)$ with a slope of 0.53 , indicating a fractional order dependence of $R p$ on concentration of $\mathrm{Ce}(\mathrm{IV})$ ion.

Generally, the order with respect to initiator is 0.5 when termination is bimolecular in free radical polymerization processes ${ }^{15}$, and it drops to nearly zero when primary radical termination predominates. The initiator rate exponent of nearly 0.5 confirms bimolecular termination in the present study. The rate of polymerization rises rapidly with [Ce(IV)] until a concentration of approximately $0.05 \mathrm{M}$ is reached; further increases in the concentration have a retarding effect on the rate of polymerization (Figure 2). The decrease of rate of 
polymerization at higher $[\mathrm{Ce}(\mathrm{IV})]$ can be accounted for by considering that at high concentrations, the oxidation and termination process increases. Similar behavior has also been reported by Fernandez et al. ${ }^{16}$

Table 2. Variation of initiator concentration

\begin{tabular}{cccc}
{$[\mathrm{AN}]=0.25 \mathrm{M},[\mathrm{AAP}]=0.002 \mathrm{M},\left[\mathrm{H}^{+}\right]=0.01 \mathrm{M}$, Temperature $=40{ }^{\circ} \mathrm{C}$, Time $=60 \mathrm{~min}$} \\
\hline $\begin{array}{c}10^{3}[\mathrm{Ce}(\mathrm{IV})], \\
\mathrm{M}\end{array}$ & $\begin{array}{c}\text { Polymer } \\
\text { weight, } \mathrm{g}\end{array}$ & $\begin{array}{c}10^{6} \mathrm{Rp} \\
\mathrm{mol} \mathrm{dm}^{-3}-\mathrm{s}^{-1}\end{array}$ & $\begin{array}{c}\% \\
\text { Conversion }\end{array}$ \\
\hline 1.0 & 0.128 & 16.752 & 5.12 \\
1.5 & 0.154 & 20.155 & 6.16 \\
2.0 & 0.173 & 22.642 & 6.92 \\
2.5 & 0.206 & 26.961 & 8.24 \\
3.0 & 0.228 & 29.890 & 9.12 \\
3.5 & 0.251 & 32.850 & 10.04 \\
4.0 & 0.274 & 35.860 & 10.96 \\
4.5 & 0.305 & 39.918 & 12.2 \\
5.0 & 0.331 & 43.320 & 13.24 \\
5.5 & 0.291 & 38.085 & 11.64 \\
6.0 & 0.273 & 35.729 & 10.92 \\
6.5 & 0.251 & 32.850 & 10.04 \\
\hline
\end{tabular}



Figure 2. Plot of rate of polymerization $v s$. initiator

\section{Effect of concentration of ligand on rate of polymerization}

The rate of polymerization was measured with different concentrations of $p$-aminoacetophenone at a fixed concentration of monomer $(0.25 \mathrm{M})$, initiator $(0.0025 \mathrm{M})$, sulfuric acid $(0.01 \mathrm{M})$ and at $40{ }^{\circ} \mathrm{C}$ for $60 \mathrm{~min}$. duration. The rate of polymerization increases with increasing ligand concentration from 0.1 to $0.5 \mathrm{M}$ (Table 3). 
The order of reaction was found to be nearly half (0.56) from the double logarithmic plot of $R p$ vs. [AAP] (Figure 3), and this suggests a bimolecular mechanism of growing polymer radical termination. This fractional order dependence on [AAP] indicates that the polymerization is initiated by primary radical with termination by mutual reaction of two growing polymer radicals.

Table 3. Variation of $p$-aminoacetophenone concentration $[\mathrm{AN}]=0.25 \mathrm{M},[\mathrm{Ce}(\mathrm{IV})]=0.0025 \mathrm{M},\left[\mathrm{H}^{+}\right]=0.01 \mathrm{M}$, Temperature $=40{ }^{\circ} \mathrm{C}$, Time $=60 \mathrm{~min}$

\begin{tabular}{cccc}
\hline $\begin{array}{c}10^{3}[\mathrm{AAP}], \\
\mathrm{M}\end{array}$ & $\begin{array}{c}\text { Polymer } \\
\text { weight, } \mathrm{g}\end{array}$ & $\begin{array}{c}10^{6} \mathrm{Rp} \\
\mathrm{mol} \mathrm{dm}^{-3} \mathrm{~s}^{-1}\end{array}$ & $\begin{array}{c}\% \\
\text { Conversion }\end{array}$ \\
\hline 1.0 & 0.150 & 19.632 & 6.0 \\
1.5 & 0.181 & 23.689 & 7.2 \\
2.0 & 0.206 & 26.961 & 8.2 \\
2.5 & 0.241 & 31.541 & 9.6 \\
3.0 & 0.260 & 34.029 & 10.4 \\
3.5 & 0.292 & 38.217 & 11.6 \\
4.0 & 0.307 & 40.180 & 12.3 \\
4.5 & 0.338 & 44.237 & 13.6 \\
5.0 & 0.366 & 47.902 & 14.8 \\
\hline
\end{tabular}

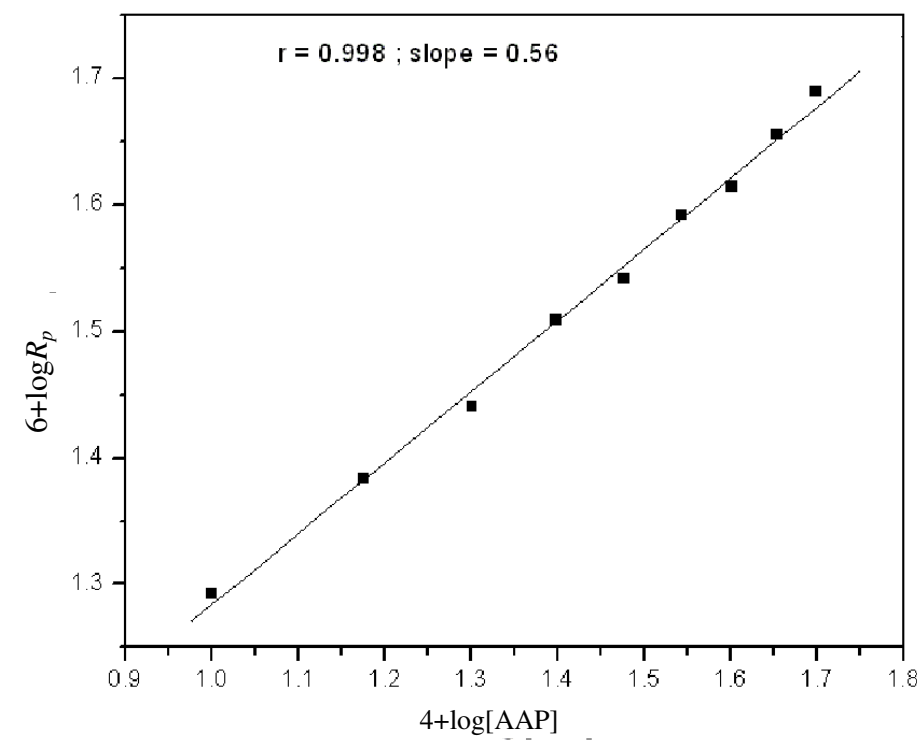

Figure 3. Double logarithmic plot for [AAP] variation

\section{Effect of concentration of acid on rate of polymerization}

The rate of polymerization was measured with different concentrations of sulfuric acid at fixed concentration of monomer $(0.25 \mathrm{M})$, initiator $(0.0025 \mathrm{M})$, ligand $(0.002 \mathrm{M})$ and at $40{ }^{\circ} \mathrm{C}$ for $60 \mathrm{~min}$ duration (Table 4). The effect of concentration of sulfuric acid on the conversion is shown in Figure 4. It is clear that the addition of sulfuric acid causes a substantial increase in rate of polymerization at lower concentration ranges and there after the rate of polymerization decreases. It is evident that at low acid concentrations, the reducing agent may be deprotonated so that the coordination becomes easier for the ceric salt 
whereas at higher acid concentrations the $R p$ decreases because the complexation may be high. The same effect has also been reported for polymerization with other oxidants ${ }^{17}$. The increase in sulfuric acid concentration causes the formation of less reactive complexes of $\mathrm{Ce}(\mathrm{IV})$ ion, which is responsible for decreasing the rate of polymerization.

Table 4. Variation of sulfuric acid concentration

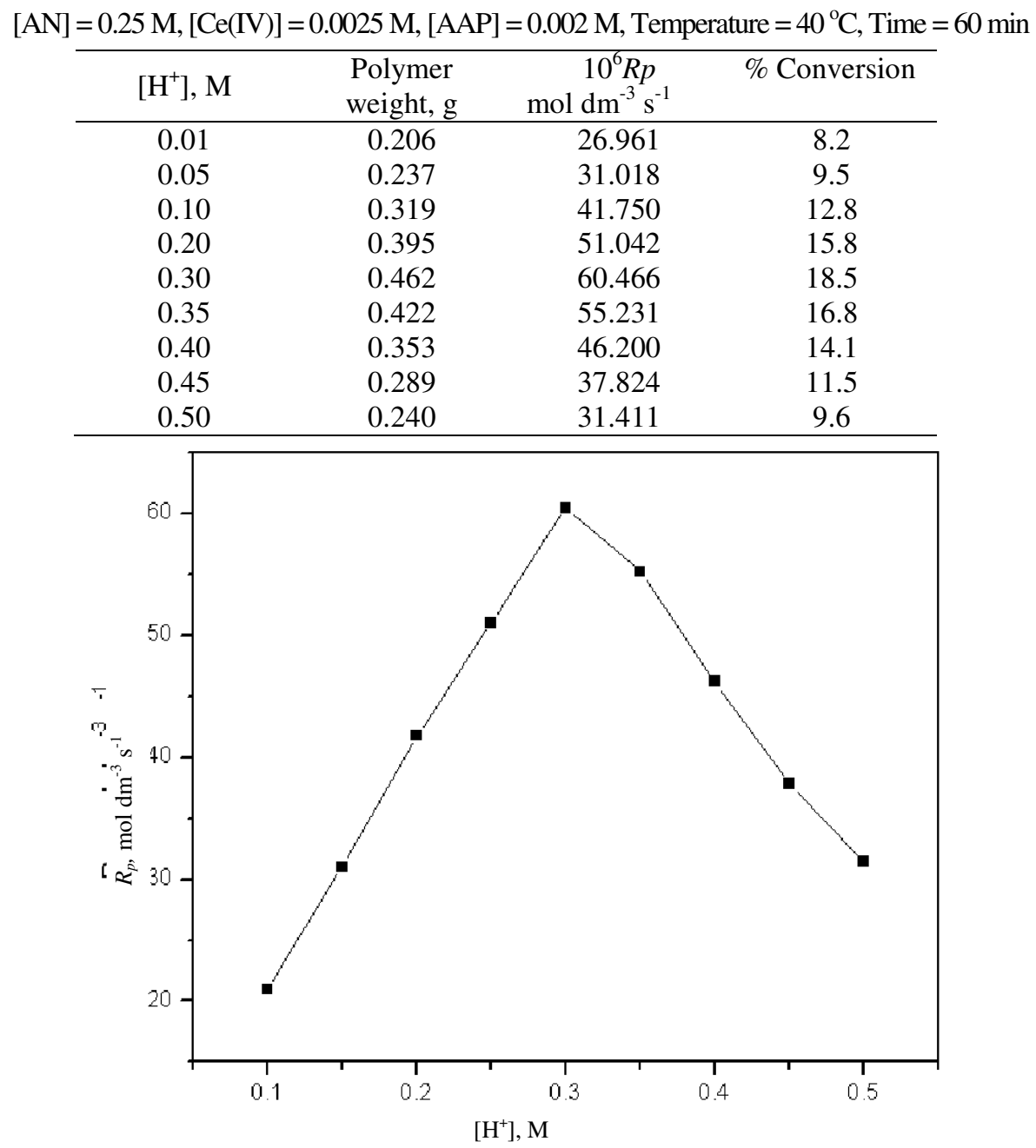

Figure 4. Effect of acid concentration on the rate of polymerization

\section{Effect of reaction temperature on rate of polymerization}

The rate of polymerization increases with an increase in temperature from $30-60^{\circ} \mathrm{C}$. This is because as the reaction rate of $\mathrm{Ce}(\mathrm{IV})$ reduction of ligand increases with temperature, there will be slow and steady generation of free radicals, and hence the polymer yield increases gradually in the temperature range $60^{\circ}-80^{\circ} \mathrm{C}$. At above $60^{\circ} \mathrm{C}$ reduction becomes very fast, resulting in an over concentration of free radicals. As high temperature causes an increase on the rates of chain termination reactions, a decrease was observed form 60 to $80{ }^{\circ} \mathrm{C}$. 
The increase in the $R p$ with increasing temperature may be attributed to: increase in the mobility of monomer and initiator molecules in the polymerization medium increase in the initiation and propagation rates of polymer. The decrease in the maximum conversion as the temperature increases may be due to the side reaction.

Thermodynamic parameters, $\mathrm{E}_{\mathrm{a}}, \Delta \mathrm{H}^{\ddagger}, \Delta \mathrm{S}^{\neq}$were calculated from Arrhenius plot (Figure 5) and as $19.357 \mathrm{~kJ}, 16.922 \mathrm{~kJ} / \mathrm{mol}$ and $-126 \mathrm{Jdeg}^{-1} \mathrm{~K}^{-1}$.

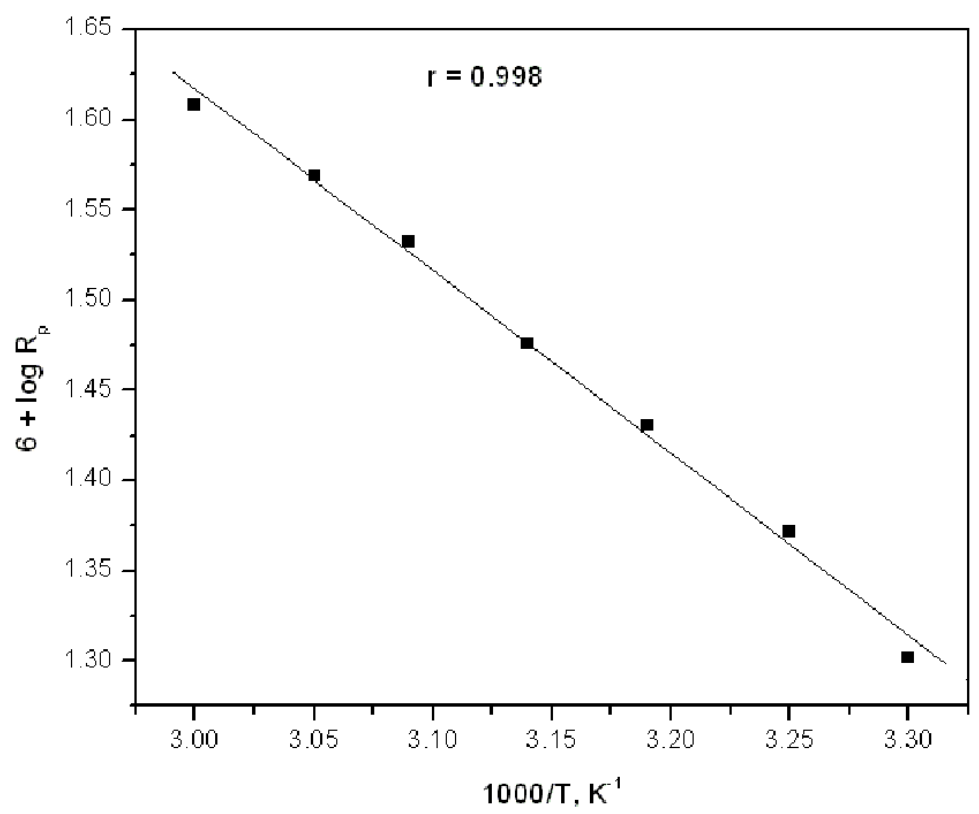

Figure 5. Arrhenius plot for the polymerization of acrylonitrile with Ce(IV)-AAP redox system

Based on the kinetic results and the thermodynamic parameters, a suitable mechanism has been proposed for the polymerization of acrylonitrile with cerium(IV) using the AAP ligand and the proposed mechanism has been supported by the derived rate law

Reaction mechanism and kinetic scheme

$$
\begin{array}{lcc}
\mathrm{Ce}(\mathrm{IV})+\mathrm{AAP} & \stackrel{\mathrm{k}_{0}}{\longrightarrow} & \mathrm{R}^{\circ} \mathrm{Ce}(\mathrm{III})+\mathrm{H}^{+} \\
\mathrm{R}^{\mathrm{o}}+\mathrm{Ce}(\mathrm{IV}) & \stackrel{K_{1}}{\longrightarrow} & \text { Product }+\mathrm{Ce}(\mathrm{III}) \\
\mathrm{R}^{\circ}+\mathrm{M} & \stackrel{\mathrm{k}_{\mathrm{i}}}{\longrightarrow} & \mathrm{RM}^{\circ} \\
\mathrm{RM}^{\circ}{ }_{\mathrm{r}}+\mathrm{M} & \stackrel{\mathrm{k}_{\mathrm{p}}}{\longrightarrow} & \mathrm{RM}^{\circ}{ }_{\mathrm{r}+1} \\
\mathrm{RM}_{\mathrm{n}}^{\circ}+\mathrm{RM}_{\mathrm{m}}^{\circ} & \stackrel{\mathrm{k}_{\mathrm{t}}}{\longrightarrow} & \text { Polymer }
\end{array}
$$

Applying the steady-state principle to the primary radicals $\mathrm{R}^{\circ}$ and the growing polymeric radicals $\mathrm{RMn}^{\circ}$ and making the usual assumption that the radical reactivity is independent of radical size ${ }^{7}$, the following equation for $R p$ can be derived.

$$
\begin{gathered}
\mathrm{D}[\mathrm{R}] / \mathrm{dt}=\mathrm{k}_{1}[\mathrm{Ce}(\mathrm{IV})][\mathrm{AAP}]-\mathrm{k}_{\mathrm{i}}\left[\mathrm{R}^{\circ}\right][\mathrm{M}], \\
{\left[\mathrm{R}^{\circ}\right]=\mathrm{k}_{1}[\mathrm{Ce}(\mathrm{IV})][\mathrm{AAP}] / \mathrm{k}_{\mathrm{i}}[\mathrm{M}]}
\end{gathered}
$$


The rate of polymerization may given by

$$
R p=\mathrm{k}_{\mathrm{p}}\left[\mathrm{RM}^{\circ}\right][\mathrm{M}], \mathrm{R}_{\mathrm{p}}=\mathrm{k}_{\mathrm{p}}\left(\mathrm{k}_{0}\right)^{1 / 2}\left(\mathrm{k}_{\mathrm{l}} / \mathrm{k}_{\mathrm{t}}\right)^{1 / 2}[\mathrm{Ce}(\mathrm{IV})]^{1 / 2}[\mathrm{AAP}]^{1 / 2}[\mathrm{M}]^{3 / 2}
$$

This rate expression explains clearly the dependence of $R p$ on AAP and monomer concentrations.

\section{Conclusion}

The kinetics of aqueous polymerization of acrylonitrile initiated by the $\mathrm{Ce}(\mathrm{IV}) / p$-aminoacetophenone redox system was studied. The proposed mechanism has been well supported by the experimental data.

\section{References}

1. Sarac A S, Progress in Polymer Science,1999, 24(1), 1149-1204; DOI:10.1016/S0079-6700(99)00026-X

2. Hülya Arslana, Baki Hazer, European Polymer Journal, 1999, 35(8), 1451-1455; DOI:10.1016/S0014-3057(98)00221-3

3. Fernández M D and Guzmán G M, J Polym Sci - A, 1989, 27(11), 3703-3720; DOI: $10.1002 /$ pola.1989.080271112

4. Narayan M S, Samal C, Mishra R and Tripathy B, J Polym Sci., 1983, 21, 407- 413; DOI: $10.1002 /$ pol.1983.170210210

5. Mahadevaiah T Demappa, Appl Polym Sci., 2007, 103, 3498-3505;

DOI: 10.1002/app.25055

6. Misra G S and Bhattacharya S N, J Polym Sci., 1982, 20, 131-136; DOI: 10.1002/pol.1982.170200114

7. Subramanian S V and Santappa M, J Macromol Chem., 1968, 1, 112-119.

8. Patnaik L N, Behera G and Rout K, Indian J Chem., 1971, 9, 432-434.

9. Fernandez M D Pelayo A, Otero T F and Guzman G M, J Polym Sci., 1985, 23,79-83; DOI: $10.1002 /$ pol.1985.130230205

10. Mino G and Kaizerman S, J Polym Sci., 1958, 31, 242-243;

DOI: $10.1002 /$ pol.1958.1203112248

11. Ananthanarayanan V S and Santappa M, J Appl Polym Sci., 1965, 9, 2437-2449; DOI: 10.1002/app.1965.070090708

12. Ratzsch M and Arnold M, J Macromol Sci., 1987, A24, 507-515; DOI:10.1080/00222338708068137

13. Rout A, Rout S P, Sing B C and Santappa M, J Macromol Sci., 1977, A11, 957-965; DOI:10.1080/00222337708061300

14. Anuradha R, Singh B C and Santappa M, Makromol Chem \& Phy., 1976, 177, 27092719; DOI: 10.1002/macp.1976.021770913

15. Balakrishnan T and Jayachadramani N, J Macromol Sci Pure Appl Chem., 1994, A31, 847-857; DOI: 10.1080/10601329409349762

16. Fernandez M D and Guzman G M, Br Polym J., 1989, 21, 413; DOI: 10.1002/pi.4980210509

17. Patra C M and Singh B C, J Appl Polym Sci., 1994, 52, 1557-1568; DOI: 10.1002/app.1994.070521104 